\title{
Trabalho Policial e Saúde Mental: Uma Pesquisa junto aos Capitães da Polícia Militar
}

\author{
Police Work and Mental Health: A Research with Military Police Captains \\ Charlotte Beatriz Spode ${ }^{\mathrm{a} *}$, Álvaro Roberto Crespo Merlo ${ }^{\mathrm{b}}$ \\ ${ }^{a}$ Universidade Regional Integrada do Alto Uruguai e das Missões, Erechim, Brasil, \\ ${ }^{\mathrm{b}}$ Universidade Federal do Rio Grande do Sul, Porto Alegre, Brasil
}

\begin{abstract}
Resumo
$\mathrm{O}$ artigo traz relato de pesquisa na qual foram abordadas as relações entre o trabalho dos Capitães da Polícia Militar e sua saúde mental, a partir dos aspectos deste ofício que geram prazer e sofrimento. Como estratégias metodológicas foram adotados três procedimentos: pesquisa documental, acompanhamento do cotidiano de trabalho e realização de entrevistas. Os resultados apontam que apesar da excessiva carga de trabalho administrativo e dos perigos inerentes à profissão, o prazer no trabalho está relacionado ao exercício de atividades de gestão, as quais proporcionam espaços de criação no trabalho. Porém, as pressões impostas pelos mecanismos disciplinares de vigilância e de controle, característicos da organização do trabalho policial militar, não deixam de constituir-se como fonte de sofrimento, pois engendram a divisão dos trabalhadores e colocam barreiras para a criação dos vínculos de confiança e cooperação, aspectos de suma importância se considerarmos a própria natureza do trabalho, permeada por riscos.

Palavras-chave: Trabalho policial; saúde mental.

Abstract

This article conveys a research report in which the relations between the work of Military Police Captains and their mental health were approached, arising from the aspects of this profession that generate pleasure and suffering. Three procedures were adopted as methodological strategies: Documental research, observation of daily work and interviews. The results show that in spite of the excessive administrative working load and perils inherent to the profession, the pleasure in work is related to management activities, which provide spaces for creating in the workplace. However, the pressures imposed by the disciplinary mechanism of vigilance and control, characteristics of the organization of military police work, constitute in itself a source of suffering. Since they engender the division of workers and impose barriers where bonds of cooperation and confidence are needed, aspects that are of great importance considering the nature of this type of work, permeated by risks.

Keywords: Police work; mental health.
\end{abstract}

Freqüentemente podemos ver a atuação dos policiais sendo veiculada pela mídia, ora mostrando ações de combate ao crime - colocando-os no lugar de heróis - ora mostrando-os como vilões, que se corrompem ou matam inocentes. O trabalho policial ocupa, portanto, um território de controvérsias, no qual se engendra uma realidade ainda pouco conhecida pela sociedade: a do policial trabalhador, cuja função é conter a violência, mas que, ao mesmo tempo, corre o risco de reproduzi-la e/ou de ser vítima dela.

Pensando o ofício policial a partir dessa perspectiva, não é difícil deduzir que se trata de uma categoria profissional bastante vulnerável à produção de sofrimento psíquico, uma vez que o exercício do trabalho é marcado por um cotidiano em que a tensão e os perigos estão sempre presentes.

\footnotetext{
* Endereço para correspondência: Rua Sofia Veloso, 120, apto. 705, Cidade Baixa, Porto Alegre, RS, 90050-040. Telef: (51) 3737-5847. E-mail: chabea@viavale.com.br

A presente pesquisa é parte da dissertação de mestrado intitulada "Ofício de Oficial: Trabalho, Subjetividade e Saúde Mental na Polícia Militar”, defendida no Programa de Pós-Graduação em Psicologia Social e Institucional da Universidade Federal do Rio Grande do Sul, no ano de 2004.
}

Em se tratando especificamente dos trabalhadores da Polícia Militar, às exigências do contexto de risco permanente vivido nas ruas, somam-se àquelas relacionadas à forma como o trabalho está organizado, marcado por um alto rigor prescritivo e alicerçado em um sistema de disciplina e vigilância também permanentes.

No presente artigo relatamos pesquisa na qual buscouse compreender as relações entre o trabalho dos Capitães da Brigada Militar - denominação que recebe a Polícia Militar no Estado do Rio Grande do Sul / Brasil - e a sua saúde mental. A escolha dos Capitães como sujeitos relaciona-se com a especificidade dos posto que ocupam, uma vez que na escala hierárquica situam-se como Oficiais Intermediários, o que significa que exercem funções de comando em relação aos Praças e Oficiais Subalternos (Tenentes) e estão, concomitantemente, subordinados aos Oficiais Superiores (Major, Tenente Coronel e Coronel). Ocupando esta posição, têm como incumbência garantir a manutenção e o cumprimento do trabalho prescrito, ao mesmo tempo em que se deparam em suas atividades, juntamente com seus subordinados, com a dimensão do chamado trabalho real, ou seja, aquela que, em contraposição aos 
modos operatórios, corresponde ao imprevisto (Dejours, 1997).

Levando-se em conta que a realização das atividades não pode nunca estar separada dos aspectos relacionais imbricados na organização do trabalho, estar nesta posição de comando intermediário implica a configuração de uma série de situações nas quais as relações no trabalho exigem elaborações, arranjos, acordo, etc. Assim, na articulação entre a gestão da defasagem existente entre o prescrito e o real e as relações intersubjetivas no trabalho, emerge uma série de aspectos que podem ser tanto fonte de prazer, quanto fonte de sofrimento para esses sujeitos.

Para realização do estudo, utilizamos como principal referencial teórico a Psicodinâmica do Trabalho, disciplina que trouxe como importante contribuição às analises da relação entre trabalho e saúde mental, a ampliação de seu entendimento para além dos quadros psicopatológicos configurados, uma vez que propõe o deslocamento do eixo de análise da loucura para a normalidade - a qual abarca tanto o sofrimento quanto o prazer no trabalho. Outra contribuição diz respeito à ênfase dada à necessidade de situar a relação entre trabalho e saúde mental dentro daquilo que a especifica como relação social (Dejours, 1994, 1999a).

Desta forma, é proposto que a análise desta temática conjugue as questões referentes à organização e relações sociais no trabalho com as vivências subjetivas de sofrimento e prazer dos trabalhadores. Para tanto, alguns aspectos devem ser considerados, e apontamos a importância que a organização do trabalho assume. Dejours (1992) a define como a esfera que abarca, por um lado, o modo operatório prescrito (conteúdo das tarefas) e, por outro, a divisão das tarefas e dos homens e mulheres pela repartição das responsabilidades, hierarquia, comando e controle (relações no trabalho). A organização do trabalho constitui-se, portanto, de uma dimensão que transcende os aspectos técnicos, pois é social e construída no lastro de uma relação intersubjetiva.

Quando abordamos a organização do trabalho a partir da Psicodinâmica do Trabalho, uma distinção de fundamental importância é aquela feita originalmente na Ergonomia, entre o trabalho prescrito e o trabalho real (Daniellou, Laville \& Teiger, 1989; Oliveira, 2002). O primeiro diz respeito àquilo que é apresentado aos trabalhadores como o que deve ser feito segundo normas e definições precisas - a tarefa a ser cumprida - cujas diretrizes geralmente são dadas considerando uma situação modelo, negligenciando as variabilidades das situações de trabalho. No entanto, trabalhar exige dar conta de uma realidade bem mais complexa do que aquela prevista pela prescrição (Barbarini, 2001). Trabalhar exige dar conta daquilo que, independente da qualidade da concepção e da precisão dos procedimentos, impõe-se inexoravelmente aos trabalhadores por meio do imprevisto, do inesperado, daquilo que foge à prescrição. Estamos, portanto, no âmbito do trabalho real (Dejours, 1997).

Assim, as atividades realizadas pelos trabalhadores implicam reajustamentos dos modos operatórios em face do real (Dejours, 1997; Oliveira, 2002), nas quais sempre restará uma parcela de responsabilidade que retornará aos trabalhadores. Nessas situações, o engajamento subjetivo é convocado mediante procedimentos e decisões que, muitas vezes, antecipam-se à consciência e à simbolização dos atos práticos, uma vez que, conforme Dejours (1997, p. 24-25), mais do que resultado lógico de um diagnóstico exato, trata-se de decisões no "sentido forte do termo, isto é, daquilo que concerne às situações inéditas para os atores, ou às situações em que a análise não pode ser liquidada a priori".

A saúde e o prazer no trabalho estão, dentro desta abordagem, justamente na possibilidade de que os sujeitos negociem com a organização prescrita do trabalho sua inscrição no domínio do trabalho real, ou seja, na possibilidade de criar. Isto porque, para Dejours (1997, p. 40), o real do trabalho é "aquilo que se faz conhecer por sua resistência ao domínio técnico e ao conhecimento científico". Ele é aquilo que "escapa" e se torna um enigma a decifrar, sendo apreendido inicialmente sob a forma de uma experiência vivida. É a partir do desafio colocado pelo real do trabalho, que o sujeito acrescenta algo de inédito ao trabalho, algo de sua autoria, por intermédio de sua ação singular sobre a tarefa e sobre as rotinas já dadas pela organização prescrita.

No entanto, é importante salientar que a inserção do sujeito entre o trabalho prescrito e o real é sempre conflitiva, e não se dá fora do contex to das relações sociais no trabalho. É nesse ponto que aparece outro elemento fundamental para que o sofrimento no trabalho ganhe sentido e se transforme em prazer e saúde: o reconhecimento. Para Dejours (1997, 1999a) este é condição indispensável no processo de mobilização subjetiva da inteligência e da personalidade no trabalho e se dá por duas vias de julgamento: o julgamento de utilidade e o julgamento de "beleza". O primeiro, como o próprio nome designa, diria respeito à utilidade técnica, social ou econômica dada à atividade singular desempenhada pelos trabalhadores. Quem estaria em condições de proferir esse julgamento seriam aqueles que, em relação ao sujeito, encontram-se em uma posição hierárquica diferente: chefes, gerentes, supervisores, e mesmo, os subordinados. O julgamento de "beleza" por outro lado, é aquele efetuado pelos pares, ou seja, aqueles que, situados na mesma faixa hierárquica e compartilhando o mesmo ofício, estão em condições de avaliar a singularidade e a "beleza" do trabalho executado. Por isso, refere-se às regras do métier, construídas através do processo de burla das regras prescritas (Merlo, 2002). Essa burla, se, por um lado necessita da discrição, por outro, precisa ganhar um certa visibilidade para fazer o sujeito ser reconhecido por seus pares. À visibilidade conjuga-se então a questão da confiança entre os trabalhadores, a qual em Psicodinâmica do Trabalho refere-se à disposição de reconhecimento do direito de cada um em obter um julgamento justo quanto ao modo como negocia com o trabalho real (Amador, 2002; Dejours, 1997).

De outra forma, quando a organização do trabalho tornase rígida, dificultando ou barrando a expressão criativa e autonomia dos sujeitos, ou ainda, quando o reconhecimento não se faz presente, emerge o chamado sofrimento patogênico (Dejours, 1994). A Psicodinâmica do Trabalho, portanto, 
situa o trabalho como um território que tanto pode dar origem a processos de alienação e mesmo de descompensação psíquica, como pode ser fonte de saúde. Nesse sentido, muito mais do que a aplicação de conhecimento técnico, o trabalho implica mobilização subjetiva, a qual se compõe e encontra ressonância em sua inserção no coletivo de trabalho.

\section{Método}

\section{Estratégias Metodológicas}

A pesquisa foi realizada no ano de 2003 em uma Organização de Policia Militar (OPM) do Estado do Rio Grande do Sul - Brasil, cuja principal atividade é a execução do policiamento ostensivo. A utilização de um método qualitativo de pesquisa deu-se a partir do entendimento que as relações do trabalhador com seu trabalho são sempre perpassadas por fatores dinâmicos e contingentes. Desta forma, para buscar elementos que permitissem a análise das implicações do trabalho na saúde mental dos Capitães, optamos pela adoção de três estratégias metodológicas interrelacionadas: pesquisa documental, acompanhamento das atividades de trabalho e a realização de entrevistas.

A pesquisa documental teve por objetivo descrever e analisar a organização prescrita do trabalho. Para tanto, foram utilizados o Estatuto dos Servidores Militares da Brigada Militar do Estado do Rio Grande do Sul ([ESMBM], Lei Complementar n. 10.990, 1997), a Lei ${ }^{\circ}$ 10.991 (1997, que dispõe sobre a Organização Básica da Brigada Militar), o Regulamento Disciplinar dos Servidores Militares do Estado do Rio Grande do Sul ([RDSM], Decreto $n^{\circ}$ 41.067, 2001), o Guia de Consultas das Diretrizes para o Policiamento Ostensivo e Notas de Instruções Operacionais da Brigada Militar (Pinheiro \& Álvares, 1993), o Manual da Brigada Militar (Comando de Policiamento da Capital, 1997) e o Edital de Concurso público para ingresso no Curso Superior de Polícia Militar, Quadro de Oficiais do Estado Maior da Brigada Militar - posto de Capitão (Estado de Rio Grande do Sul, 2002).

O acompanhamento das atividades administrativas e operacionais dos Capitães - perfazendo um total aproximando de 80 horas - teve por objetivo ver como estas efetivamente acontecem no cotidiano e foi registrado em diário de campo.

Foram realizadas ainda sete entrevistas gravadas, nas quais buscou-se captar as percepções e as vivências subjetivas decorrentes da experiência de trabalho para, assim, analisar as relações entre trabalho e saúde mental a partir dos elementos descritos pelos entrevistados como geradores de prazer e sofrimento.

\section{Perfil dos Entrevistados}

Uma vez que os Capitães podem desenvolver diversas funções dentro de uma OPM, utilizamos como critério para escolha dos sujeitos de pesquisa o fato de estarem desenvolvendo, à época da pesquisa, funções voltadas diretamente para o policiamento, ou então, terem atuado nessa área recentemente. Todos os participantes são homens, com idades entre 29 e 40 anos e fizeram o Curso Superior de For- mação de Oficiais da Brigada Militar na Academia de Policia Militar, cuja duração, conforme a época de realização, variou entre três e quatro anos. Antes de chegar ao posto de Capitão, passaram pela etapa de Aspirante e pelos postos de Segundo-Tenente e Primeiro-Tenente. Tinham entre 10 e 20 anos de tempo de serviço na Brigada Militar e entre três e cinco anos no posto de Capitão. Cabe salientar que participação na pesquisa não teve caráter convocatório, mas sim voluntário, ou seja, após apresentação da proposta de pesquisa, os Capitães foram convidados a participar e uma vez tendo aceitado, assinaram um Termo de Consentimento Pós-Informação.

\section{Resultados e Discussão}

\section{O Trabalho Prescrito}

A análise do trabalho prescrito, realizada a partir dos documentos anteriormente listados, permite definir a Policia Militar o órgão integrante da segurança pública, que tem como atribuição exclusiva a realização do policiamento ostensivo, assegurando o cumprimento da lei e a manutenção da ordem.

Quanto às atribuições prescritas para o cargo de Capitão, estas são: exercício da polícia ostensiva, compreendendo planejamento, controle, supervisão e execução de ações policiais; comando de Órgãos de Polícia Militar e chefia de seções de escalão intermediário, com gestão de recursos humanos, logísticos, patrimoniais, financeiros e operacionais de polícia ostensiva; realização de atos de gestão de polícia administrativa; ministrar treinamentos ao efetivo sob sua responsabilidade; presidir inquéritos policiais militares; proceder a verificação e exame dos atos ilícitos que tomar conhecimento, tomando as providências jurídicas que o caso requer; presidir processos administrativos disciplinares; proceder inquéritos técnicos e sindicâncias administrativas e expedir e fiscalizar a emissão de documentos públicos de sua competência.

O exercício da polícia ostensiva engloba, ainda, a realização de Serviços Externos de doze horas, organizados no formato de escalas e as quais concorrem todos os Oficiais que atuam na OPM. O Oficial de Serviço é responsável, durante o período, pelo comando de postos externos de policiamento de toda a área de abrangência da OPM e dentre suas competências estão, conforme a Diretriz de Policiamento Ostensivo $n^{\circ} 9$ (Pinheiro \& Álvares, 1993): manter-se constantemente nas Subáreas de ação exercendo a fiscalização segundo roteiro estabelecido, assumir a responsabilidade por todos os praças de serviço nos postos externos; coordenar, controlar e apoiar os serviços de policiamento ostensivo, respeitando as Ordens de Serviços emanadas pelos Comandantes de Subáreas e Setores; administrar a Sala de Operações, que lhe estará subordinada e comparecer em ocorrências, quando chamado pelos elementos de serviço, quando estes se julgarem incapazes de resolvê-las, tomando as providências cabíveis.

Ganha relevância na organização do trabalho policial militar o fato de que esse está alicerçado em duas pautas principais: a hierarquia e a disciplina. Assim, foi possível 
identificar, a partir da análise documental, uma gama de prescrições e um sistema de punições e recompensas que incidem diretamente na execução do trabalho, nas relações que se estabelecem entre os policiais e também, de forma mais ampla, aos princípios que devem pautar a conduta destes, mesmo fora do ambiente de trabalho.

O documento que se ocupa mais diretamente das questões relativas ao cumprimento das prescrições e manutenção dos princípios da hierarquia e da disciplina é o Regulamento Disciplinar dos Servidores Militares (Decreto $\mathrm{n}^{\circ}$ 41.067, 2001), e nele podemos encontrar 94 (noventa e quatro) tipos de transgressão, que estão classificadas quanto à sua natureza em leves, médias e graves, sendo todas passíveis de sanção disciplinar, variando seu grau de acordo com a natureza das faltas cometidas.

Em relação às prescrições para as relações entre os policiais, destaca-se que todo policial militar deve, segundo os preceitos da ética e do dever policial militar (Lei Complementar n. 10.990, 1997), cumprir rigorosamente as obrigações e as ordens; praticar a camaradagem e desenvolver permanentemente o espírito de cooperação; tratar os subordinados com dignidade e urbanidade; zelar pelo preparo moral, intelectual e físico, próprio e dos subordinados, tendo em vista o cumprimento da missão comum e ser justo e imparcial no julgamento dos atos e na apreciação do mérito dos subordinados (Arts. 25 e 29). Estará incorrendo em transgressão todo subordinado que deixar de cumprimentar seu superior, ou deixar de prestar-lhe homenagem ou sinais regulamentares de consideração e respeito; assim como o superior hierárquico incorrerá, caso não responda ao cumprimento. Também poderá ser punido o policial militar que responder de maneira desrespeitosa, ofender, provocar ou desafiar com palavras, gestos ou ações ou travar luta corporal com seu superior, igual ou subordinado e ainda, o policial militar que censurar publicamente decisão legal tomada por superior hierárquico ou procurar desconsiderá-la (Decreto $\mathrm{n}^{\circ} 41.067,2001$ ).

Após esta breve descrição do trabalho prescrito, apresentaremos a seguir alguns dos principais aspectos do trabalho cotidiano dos Capitães, juntamente com a análise dos elementos apontados pelos entrevistados como geradores de sofrimento e prazer no trabalho.

Atividade Administrativa: Carga Excessiva de Trabalho, Responsabilidade e Autonomia

Os Capitães participantes da pesquisa, como comandantes de Companhias ou Pelotões, tinham sob responsabilidade um efetivo que pode variar de 25 a 75 policiais. A atribuição de planejamento de policiamento desdobra-se em uma série de atividades, dentre elas, a realização de estatísticas para averiguar os locais mais propensos a ocorrências e o planejamento de cada um dos postos de policiamento da subárea sob seu comando. Em relação à gestão de recursos humanos, dentre as atividades envolvidas, está o planejamento das escalas de trabalho dos Praças para os quatro turnos de trabalho, a concessão de licenças e o gerenciamento das folgas e férias de seus subordinados.
Os Capitães também se envolvem com o controle, manutenção e distribuição e dos equipamentos de trabalho.

Dentre as atividades administrativas, ganha destaque a presidência dos chamados Procedimentos, processos que visam investigar possíveis infrações disciplinares cometidas por policiais militares, e que englobam Inquéritos Técnicos, Sindicâncias Administrativas, Inquéritos Policiais Militares e Procedimentos Administrativos Disciplinares, cada um dos quais com formato e prazos são específico. Desde a elaboração até a conclusão dos Procedimentos, existe um formalismo bastante minucioso a ser cumprido. Por tratarem-se de processos oficiais, é necessária muita atenção para evitar erros ou omissão de dados, a qual, pode, inclusive, ser classificada como transgressão disciplinar e resultar em punição. Além disso, a condução de cada um dos Procedimentos exige que diversas atividades sejam executadas, tais como: encaminhamento de perícias junto aos setores competentes nos casos de Inquéritos Técnicos, envio de ofícios solicitando a presença dos acusados ou das testemunhas para serem ouvidos e a tomada dos depoimentos dos envolvidos.

Neste sentido, a presidência dos Procedimentos, foi considerada unanimemente pelos entrevistados, como a "a parte ruim e chata do trabalho”. As deficiências das condições de trabalho e o fato de dependerem de outras pessoas para realizá-los, como peritos (que muitas vezes demoram a entregar os laudos necessários ao andamento dos processos) e depoentes (que não raras vezes, deixam de comparecer no dia e horário estipulados) são fonte de pressão, visto que o atraso na entrega pode resultar em punição, pois dentre as transgressões de natureza média, listadas no RDSM, consta "deixar de encaminhar documentos no prazo legal". Nas palavras de um Capitão:

Não gosto de fazer sindicância, não gosto de fazer inquérito, não gosto de ouvir as pessoas em inquérito e sindicância. Por quê? Porque é um problema, porque ou não tem o computador, ou tu não tem horário, ou a pessoa que tu chamava não vem, aí... Sabe? $\mathrm{E}$ isso, junto com a parte operacional e até mesmo com outras questões administrativas, isso me causa um estresse tremendo. Eu não gosto de fazer procedimento. Não gosto mesmo.

Assim, o grande número de atribuições no âmbito administrativo, sobretudo em função dos Procedimentos, faz com que, regularmente, os Capitães tenham que iniciar mais cedo ou estender o horário de trabalho para além das seis horas diárias estipuladas. Neste sentido, os entrevistados atribuem a elevada carga de trabalho o fato de tornar a sua profissão desgastante.

A essa questão associa-se a disponibilidade permanente demandada pelo trabalho, em função das responsabilidades do cargo, sobretudo no que tange à execução do policiamento nas subáreas que estão sob comando dos Capitães. Trata-se de uma responsabilidade que não cessa mesmo quando eles não estão em horário de trabalho, a qual os faz não poderem "desligar nunca", engendrando um estado de preocupação constante, como relatou um dos entrevistados: 
Eu tenho responsabilidade sobre os bairros que tão sob o meu comando. Aconteça o que acontecer, eu continuo tendo responsabilidade territorial. A gente cuida 24 horas. Embora tenha um Oficial que fique de serviço, embora tenham as outras guarnições de serviço, sargentos e tal. Mas a responsabilidade, ela não pára. Os caras me ligam: olha, deu problema na tua subárea, não sei o que, tal. Tu pode até não ir no local, mas a gente já fica preocupado com o aconteceu. Então é isso, a nossa responsabilidade não cessa. A gente tá sempre preocupado.

No entanto, é preciso lembrar que estes aspectos nem sempre são incompatíveis com o prazer que é obtido na relação estabelecida com o trabalho (Dejours \& Jayet, 1994). Nesse sentido, os Capitães afirmam também que encontram grande satisfação na profissão de policiais militares, e mais especificamente no posto que ocupam. Dentre os fatores que trazem satisfação, está a percepção que têm da importância social do trabalho, a despeito das inúmeras críticas feitas em relação à atuação da polícia:

Só nosso trabalho em si já é uma coisa gratificante, é um serviço que a gente ta prestando pra comunidade. Pensa bem, uma cidade sem policiamento, por exemplo? Se com policiamento já acontece muita coisa, então o nosso serviço é muito importante pra sociedade. Então só de a gente se sentir necessário, já e uma coisa gratificante pra gente.

Esse "sentir-se útil”, se está vinculado ao objetivo mais amplo do trabalho, qual seja, a preservação da segurança pública, remete também à participação de cada um dos Capitães nesse processo, pelas atividades de concepção. Lembramos que do ponto de vista da saúde mental, o engajamento subjetivo, pela mobilização da inteligência e da inventividade no trabalho é um aspecto de suma importância para garantir que este seja fonte de prazer (Dejours, 1992, 1997; Merlo, 2002). Ao mesmo tempo, ainda que muitas determinações que tenham de ser cumpridas, existe um espaço de autonomia que permite adaptálas e decidir sobre como serão realizadas, como pode ser visto na fala a seguir:

Cada Oficial tem uma maneira de ser, uma maneira de tu levar. É como um dirigente, o treinador e os jogadores. Tem o dirigente que contrata o treinador, eu sou o treinador. Ele quer que o time atue de determinada forma e o treinador vai dar o seu toque pessoal e o soldado dentro de campo, o jogador. Tu chega e verifica qual a melhor maneira de tu fazer aquilo que foi solicitado prá ti fazer.

Assim, ainda que o trabalho dos Capitães seja permeado de pressões, é fonte de prazer, por ser tributário de uma utilidade social que lhe atribui um sentido e pela possibilidade de singularização no espaço de autonomia e criação que proporciona.

\section{Atividade Operacional: Risco, Sofrimento e Prazer}

A presença dos Capitães diretamente na atividade de policiamento se dá basicamente de duas formas: quando saem às ruas para coordenar, fiscalizar e suplementar efetivo do Policiamento Ostensivo, durante o turno diário de trabalho, ou então, para realização dos Serviços Externos de doze horas, que podem acontecer durante o dia, das sete da manhã às sete da noite, ou das sete da noite às sete da manhã. No período em que estão no Serviço Externo, os Capitães são a instância máxima de responsabilidade e autoridade nas ruas. Em relação ao conteúdo do trabalho, as principais tarefas são fiscalizar o policiamento em toda área da OPM, verificando se os Praças estão nos locais estipulados e cumprindo as determinações para o policiamento e dar apoio e resolver problemas nas ocorrências.

O trabalho policial situa-se entre as categorias profissionais em que à exposição aos riscos relacionados à integridade física são evidentes, sobretudo quando se trata da atividade operacional. Nesse sentido, a falta de condições de trabalho adequadas é apontada pelos Capitães como um fator de pressão também neste âmbito, em função dos perigos impostos pela precariedade dos equipamentos. Além de sua própria segurança, frisam os efeitos desta precariedade sobre a segurança da população e dos próprios combatidos.

O trabalho nas ruas é referido pelos Capitães como uma "caixa de surpresas", pois nunca sabem com que tipo de situações irão se deparar e neste sentido, afirmam que precisam estar preparados para as ocorrências mediante o conhecimento da legislação e dos procedimentos prescritos para serem adotados frente a elas. No entanto, afirmam que todas as ocorrências são diferentes. São estas diferenças entre uma situação e outra que trazem para o trabalho operacional a dimensão do real, ou seja, daquilo que não pode ser previsto e que, por isso, não pode ser solucionado unicamente a partir da aplicação dos procedimentos prescritos. Coloca-se, portanto, inevitavelmente, uma defasagem entre a dimensão prescrita e a real do trabalho que só poderá ser gerida pelo engajamento da subjetividade dos trabalhadores (Dejours, 1997).

Esse engajamento recebe em Psicodinâmica do Trabalho a denominação de "inteligência astuciosa" ou "prática”, mobilizada frente ao real e que tem como característica fundamental a inventividade e a criatividade (Dejours, 1997). Ela implica necessariamente a interpretação dos trabalhadores, na tomada de uma decisão frente à situação e também, na assunção dos riscos que decorrem dela. Neste ponto, é importante lembrar que, no caso dos Capitães, a responsabilidade e a tomada de decisões estão vinculadas ao próprio estatuto da função de comando que ocupam.

$\mathrm{Na}$ atividade operacional, ao contrário do que ocorre na administrativa, na qual as decisões podem ser tomadas com mais tempo para reflexões e consultas, a tomada de decisões tem que ser, na maioria das vezes imediata e implica, portanto, assumir riscos maiores de errar. Sobrepõe-se a isso o fato de que, em geral, trata-se de situações tensas e nas quais estão em jogo segurança e não raramente a vida de pessoas: a sua, a dos subordinados e da dos civis envolvidos, como na experiência relatada por um dos entrevistados:

Foi quando eles (assaltantes que mantinham reféns) me exigiram eu entrar desarmado, o que eu fiz. Foi uma decisão que eu tive que tomar no momento. E na hora a gente quer resolver o 
problema, a gente tá preocupado com a vida das pessoas. Foi uma decisão que eu tive que tomar, simplesmente tirei minha arma da cintura, entreguei pro PM e entrei.

Assim, as decisões tomadas não decorrem estritamente da execução de determinados procedimentos e não são os resultados de um diagnóstico exato sobre uma situação - o qual não pode ser obtido até mesmo em função do tempo mínimo em que têm de ser tomadas. São decisões que em muitos casos antecipam-se à racionalização, tomadas a partir da mobilização da subjetividade frente ao imprevisto e ao incerto (Dejours, 1997).

Ainda que a intenção seja sempre de tomar uma decisão acertada, de garantir que a ocorrência termine bem, com a vida e a segurança dos envolvidos assegurados, tal garantia nunca existe. Os Capitães admitem que há situações que fogem ao controle, como pode ser visto na seguinte fala:

Eu vou te dizer sinceramente, partindo por mim, eu falo dos outros Oficiais que estão na rua aí, todos nós queremos acertar. Todo mundo que tá na rua quer acertar. Muitas vezes no quente da ocorrência acaba acontecendo alguma coisa que a gente não previu ou que a gente não quis. Mas acontece, vai acontecer. Um tiroteio, uma pessoa ferida que não era pra ser ferida e foi ferida, alguma... Muitas vezes até, no afã de capturar um delinqüente, passar no pátio de alguém ou então abordar um carro e mandar todo mundo sair, porque era o carro do suspeito, mas daí tu vê que não era aquele carro. Então algumas coisas assim acontecem e são atribuídas a nós como abuso de autoridade, invasão de domicílio...

Essa afirmação remete às situações nas quais a execução do trabalho exige não somente suprir as insuficiências da organização prescrita, mas nas quais está colocada também a possibilidade de transgredi-la ${ }^{1}$. Tais situações apresentam um paradoxo que diz respeito ao fim máximo colocado para a atividade policial, qual seja, a preservação da vida e da segurança. Neste sentido, as transgressões cometidas pelos policiais podem assumir um caráter muito grave, quando tiverem como conseqüência, por exemplo, a morte de alguém. No entanto, em muitos casos, agir com o objetivo de proteger pode passar pela necessidade de transgressão de alguma norma.

Este paradoxo é potencializado pelo fato de que, se e por um lado a transgressão torna-se, em muitos casos inevitável, por outro, sempre pode ser passível de punição. Coloca-se, assim, um impasse para os policiais: a mesma transgressão que pode ser necessária ao trabalho traz riscos para a segurança, bem como o risco da punição. Desta forma, conforme os Capitães, não há outra opção senão assumir os riscos e admitir que a punição e o louvor fazem parte da vida de todo policial, sobretudo para aqueles que estão exercendo atividades operacionais: "Então, a maioria dos Oficiais, vou te dizer bem sincero, a

\footnotetext{
${ }^{1}$ É preciso esclarecer que a afirmação de que é necessário transgredir para trabalhar parte dos autores e não dos policiais. A palavra transgressão, no universo policial militar adquire um sentido diferente do que o utilizado no referencial teórico adotado neste estudo. Enquanto no primeiro caso ela é definida como a violação do dever policial militar (RDSM), sendo, portanto carregada de um teor pejorativo; no segundo ela caracteriza a incursão dos trabalhadores em práticas que não estão previstas nas regras ou nos regulamentos do trabalho, em muitos casos, a única forma de conseguir realizar as tarefas (Dejours, 1999b).
}

maioria do pessoal que realmente tá na rua, sabe que tá propenso a ser punido, ou a ser responsabilizado."

A possibilidade de punição sempre presente é um aspecto que parece causar sofrimento aos Capitães, pois implica o custo subjetivo de transitar sempre por uma linha tênue entre ser considerado um herói ou ser um vilão, entre ser considerado um bom ou um mau profissional, competente ou incompetente.

No entanto, ao serem questionados sobre o tipo de atividade que mais gostam mais de realizar, os Capitães foram unânimes em afirmar que é a operacional, mesmo cercada de tantos riscos e tensão. Nos Serviços Externos, como já referido, a responsabilidade aumenta consideravelmente, mas, em contrapartida, a autonomia é maior, elemento que aparece novamente vinculada ao prazer no trabalho, como pode ser visto neste relato:

Deve até ter um lado até um pouco estranho nisso, mas eu até gosto. Eu gosto quando eu tenho autonomia prá fazer o quê e como eu acho. Porque aí não tem ninguém interferindo. Eu gosto quando é tudo comigo, eu prefiro isso.

Os Capitães destacam também a satisfação que sentem quando conseguem solucionar conflitos, recuperar bens ou salvar a vida de pessoas. Nestas, situações há a possibilidade de um produto "concreto" (positivo, nestes casos) do trabalho, diferentemente do que ocorre na atividade preventiva, uma vez que nesta - embora não considerada menos importante por eles - é justamente a não ocorrência de delitos o produto do trabalho. Conforme um dos entrevistados: "No fundo, todo policial militar ele gosta e ele se sente valorizado quando ela consegue pegar uma ocorrência e atender uma ocorrência a bom termo. É bom isso, eleva o ego do policial”.

São essas situações, segundo os Capitães, que os fazem sentir mais significativamente o prazer de serem policiais. Neste sentido, referem-se não somente ao resultado positivo, mas também ao processo que tornou possível o êxito: terem sabido conduzir a ocorrência e tomar decisões acertadas, mesmo sob risco, pressão e com pouco tempo para pensar. O que parece estar colocado é o prazer por terem vencido, valendo-se do engajamento de sua subjetividade, a resistência do real do trabalho. Assim, mesmo que a ação não tenha sido realizada individualmente, esta vitória remete à contribuição de cada um, de forma singular, no trabalho.

\section{As Relações de Trabalho: Um Território de Contradições}

A organização prescrita do trabalho policial militar com seu sistema de punições e recompensas tem no disciplinamento o seu elemento central. Assim, analisar as relações que se produzem entre trabalhadores nesta instituição exige levar em consideração que estas estão sempre permeadas pela hierarquia, pela disciplina e pelos mecanismos utilizados para sua produção e manutenção. Os Capitães, por ocuparem o posto de Oficial Intermediário, estão, concomitantemente, expostos a tais mecanismos e têm a incumbência e de fazê-los funcionar na convivência com seus subordinados. Cabe-lhes, além do planejamento e gestão, o papel de "olhar hierárquico" (Foucault, 2002, p. 143) 
sobre seus subordinados, fazendo a vigilância e a fiscalização do trabalho e da disciplina, sob pena de que eles próprios sejam punidos, caso deixem de comunicar quaisquer atos contrários a esta, deixem de tomar as providências cabíveis para que sejam investigados ou deixem de punir, dentro de sua competência, os transgressores.

É importante destacar que a vigilância da disciplina, apesar do componente hierárquico em função da organização piramidal, é prescrita entre todos os policiais, fazendo dos Capitães "fiscais perpetuamente fiscalizados" (Foucault, 2002, p. 148). A disciplina, portanto, constitui-se, tal como afirma Foucault (2002), em um poder múltiplo, que atua formando uma rede que controla continuamente também os que estão encarregados de controlar. Temos assim, uma polícia que atua como polícia de si mesma, mediante a prescrição para a denúncia.

Embora não possamos esquecer que estamos nos reportando a trabalhadores que atuam na segurança pública e que, neste sentido, a vigilância objetiva o impedimento de transgressões que podem ser a prática de atos ilícitos e/ou criminosos, claramente incompatíveis com o trabalho na policial, é preciso lembrar também que este controle atua diretamente sobre o vínculo de confiança entre os trabalhadores.

A confiança, a partir do referencial da Psicodinâmica do Trabalho (Dejours, 1994, 1999b), situa-se como importante elemento na dinâmica prazer/sofrimento no trabalho, a medida em que é necessária para o estabelecimento de relações de cooperação no coletivo e para o reconhecimento do valor profissional de cada membro deste. O vínculo de confiança, no entanto, só pode ser construído a partir da equidade dos julgamentos de outros sobre o modo como cada um negocia com as dificuldades impostas pelo real do trabalho (Dejours, 1997). Implica, portanto, assumir que existe uma diferença entre o trabalho prescrito e o real e que sua gestão no trabalho policial, sobretudo na atividade operacional passa pela tomada de decisões, na maioria das vezes imediatas, e ainda, que, em muitas ocasiões, trabalhar significa ter que transgredir as normas.

Os superiores, e neste caso especificamente os Capitães, estão, portanto, diante de um conflito importante, pois, mesmo sabendo e se defrontando com os desafios colocados pelo real do trabalho, eles têm a atribuição de cumprir e aplicar as prescrições e fazer funcionar os mecanismos que visam a sua observância, estando sob a contínua ameaça de serem punidos caso não o façam:

A nossa conduta funcional tem que ser correta, senão tá sujeito ao Regulamento Disciplinar dos Servidores Militares do Estado do Rio Grande do Sul. E esse regulamento é de uma forma assim, que se um subordinando meu comete algum tipo de conduta que tá prevista como transgressão e eu não adoto a providência correta, aí vem pra mim a punição por não ter adotado... não sei o quê. Então eu não tenho como escapar disso.

Assim, não é difícil perceber que este mecanismo, a prescrição para a denúncia, engendra a divisão e a desconfiança e incrementa a animosidade entre Oficiais e Praças. Surgem daí uma série de conflitos entre os policiais, explicitados diretamente ou não - uma vez que outra prescrição diz que as relações de trabalho devem ser as melhores possíveis os quais, via de regra, não são atribuídos às contradições colocadas pela própria organização do trabalho, mas à conflitos de ordem interindividual (Dejours, 1994). Nas palavras de um capitão:

Tu passa a ter raiva, sentir raiva de determinadas pessoas por causa de atos, por causa de coisas. Como eu digo, guardar rancor, aí tu tem que ir trabalhando aos poucos aquilo ali pra ver se tu tira aquelas idéias da cabeça.

Outro ponto que gostaríamos de destacar refere-se à questão da avaliação e do julgamento. As prescrições para a imparcialidade e impessoalidade, do ponto de vista da organização do trabalho, têm como finalidade garantir, tanto no que diz respeito às relações entre os policiais como com a população e os combatidos, o maior grau de objetividade possível. No entanto, nos julgamentos realizados internamente na polícia militar, temos concomitantemente o rigor dos regulamentos e das leis e o poder discricionário, ou seja, aquele que leva em consideração não só as leis e os regulamentos, mas também a interpretação de quem está encarregado de julgar.

Assim, ao lado da objetividade e a imparcialidade conclamada institucionalmente está a implicação constante - e inevitável - da subjetividade e dos valores morais daquele que julga. É a partir dessas questões que gostaríamos de abordar o reconhecimento no trabalho. Este é - juntamente com a possibilidade de autonomia - fundamental para que os riscos psíquicos e somáticos colocados pelas pressões do trabalho possam ser subvertidos e transformados em prazer. Conforme Dejours (1999b), enquanto a criação é o elemento que permite o engajamento da subjetividade para contribuir com a organização do trabalho, fazendo os sujeitos estabelecerem uma relação de comprometimento com os objetivos dessa, o reconhecimento é a contrapartida simbólica que vai garantir a manutenção deste compromisso e, ao mesmo tempo, gerar prazer.

Ainda dentro do referencial teórico da Psicodinâmica do Trabalho, o reconhecimento está relacionado, quando parte das chefias e superiores, com o julgamento da utilidade do trabalho (Dejours, 1997), como já referido. No caso da Polícia Militar, tal julgamento adquire visibilidade institucional a partir dos processos formais de avaliação. Ocorre que, devido à forma estes são realizados, sempre perpassados por valores morais e pessoais ${ }^{2}$, eles vão se distanciando do conteúdo do trabalho e de critérios técnicos. Assim, a manutenção de um bom relacionamento com o superior passa a ser muito importante para garantir o reconhecimento institucional.

\footnotetext{
2 O processo tem como ponto de partida a avaliação realizada pelo superior direto, através de conceitos emitidos pelo avaliador, quanto a vários aspectos da conduta do Oficial, que podem variar de "Excelente" a "Insuficiente". Destacase que, na ficha de conceitos os tópicos de avaliação dizem respeito não só ao desempenho técnico, mas também a aspectos que obrigatoriamente, passam pelo julgamento moral da conduta do avaliado, tais como "lealdade e amor à verdade", "energia e perseverança", "espírito de disciplina", "correção de atitudes e uniformes", e "conduta civil".
} 
Desta forma, pode-se dizer que o não-reconhecimento do trabalho efetivamente realizado e do empreendimento de esforços para realizá-lo com qualidade podem ser fonte de sofrimento para os Capitães. Em função dessa realidade, o tipo de reconhecimento em relação às contribuições ao trabalho que parece ser mais significativo para os Capitães é aquele que provém dos pares e dos subordinados, e que não passa por processos formais de avaliação, mas, sim, por sua expressão no cotidiano de trabalho. São os pares, e no caso dos Capitães, também os subordinados em função do fato de compartilharem nas ruas vivências semelhantes no que diz respeito aos desafios colocados pelo real do trabalho - que estão em condições de afirmar a pertença daquele sujeito ao coletivo de trabalho e também, de julgar a "beleza" do trabalho executado, no sentido proposto por Dejours (1997), ou seja, como a afirmação de sua contribuição singular. Is to pode ser visto no relato de um dos entrevistados:

A gente saber que fez um bom trabalho, não eu analisando o meu trabalho, mas esse trabalho sendo analisado pelo outros, pelos colegas, até mesmo pelos que estavam sob o nosso comando, aí sim é gratificante, ser reconhecido principalmente por quem estava subordinado a nós... É muito bom, me sinto super bem.

O conteúdo abordado sobre as relações que se estabelecem entre os policiais evidencia que elas têm um papel fundamental nas vivências de prazer e de sofrimento no trabalho. Neste sentido, os maiores desafios para que as relações intersubjetivas possam abarcar o vínculo de confiança e o reconhecimento parecem estar na própria forma como é organizado o trabalho e nos mecanismos disciplinares, uma vez que esta organização oferece pouquíssimos espaços para que trabalho e os desafios por este colocados possam ser efetivamente discutidos.

\section{Considerações Finais}

Esta pesquisa, em relação a outros estudos realizados tendo como sujeitos os Praças da Polícia Militar (Amador \& Spode, 2002; Barcellos, 1999) permitiu evidenciar que, em comparação aos últimos, os Oficiais encontram no trabalho, maiores espaços para criar e exercer suas singularidades.

No entanto, foi possível constatar que a excessiva carga de trabalho administrativo - que demanda o aumento do número de horas dedicadas ao trabalho - aliada às precariedades das condições de trabalho tanto no que tange à esfera administrativa quanto à operacional, é fator significativo de pressão e desgastes para os Capitães. Da mesma forma, assim como os demais policiais militares, independente da posição hierárquica, estão submetidos aos efeitos e ao sofrimento imposto pela organização do trabalho, sobretudo em função das pressões impostas pelos mecanismos disciplinares de vigilância e de controle que engendram a divisão dos trabalhadores e que colocam barreiras para a criação do vínculo de confiança e de cooperação, aspectos de suma importância se considerarmos a própria natureza do trabalho, permeada por riscos.

\section{Referências}

Amador, F. S. (2002). Violência policial: Verso e reverso do sofrimento. Santa Cruz do Sul, RS: Editora da Universidade de Santa Cruz do Sul.

Amador, F. S., \& Spode, C. B. (2002). Por um programa preventivo em saúde mental do trabalhador na Brigada Militar. Revista Ciência e Profissão, 3, 54-61.

Barbarini, N. (2001). Trabalho bancário e reestruturação produtiva: Implicações no psiquismo dos trabalhadores. Dissertação de Mestrado não-publicada, Programa de Pós-Graduação em Psicologia Social e Institucional, Universidade Federal do Rio Grande do Sul, Porto Alegre, RS.

Barcellos, J. A. P. (1999). As condições e a organização de trabalho dos policiais que executam o policiamento ostensivo: Um estudo de caso na Brigada Militar em Porto Alegre/RS. Dissertação de Mestrado não-publicada, Programa de Pós-Graduação da Escola de Administração, Universidade Federal do Rio Grande do Sul, Porto Alegre, RS.

Comando de Policiamento da Capital. (1997). Manual da Brigada Militar - Guia de serviços do Comando de Policiamento da Capital. Porto Alegre, RS.

Daniellou, F., Laville, A., \& Teiger, C. (1989). Ficção e realidade do trabalho operário. Revista Brasileira de Saúde Ocupacional, 68, 7-13.

Decreto $n^{\circ} 41.067$ (2001). "Regulamento Disciplinar dos Servidores Militares do Estado do Rio Grande do Sul.” Diário Oficial do Estado, promulgado em 24 de setembro de 2001. Porto Alegre, RS.

Dejours, C. (1992). A loucura do trabalho-Estudo em psicopatologia do trabalho. São Paulo, SP: Cortez.

Dejours, C. (1994). Trabalho e saúde mental: da pesquisa à ação. In M. I. S. Betiol. (Ed.), Psicodinâmica do trabalho - Contribuições da escola dejouriana à análise da relação prazer, sofrimento $e$ trabalho (pp. 45-65). São Paulo, SP: Atlas.

Dejours, C. (1997). O fator humano. Rio de Janeiro, RJ: Fundação Getúlio Vargas.

Dejours, C. (1999a). A banalização da injustiça social. Rio de Janeiro, RJ: Fundação Getúlio Vargas.

Dejours, C. (1999b) Conferências brasileiras: Identidade, reconhecimento e transgressão no trabalho. São Paulo, SP: Fundação Getúlio Vargas.

Dejours, C., \& Jayet, C. (1994). Psicopatologia do trabalho e organização real do trabalho em uma indústria de processo: Metodologia aplicada a um caso. In M. I. S. Betiol. (Ed.), Psicodinâmica do trabalho - Contribuições da escola dejouriana à análise da relação prazer, sofrimento e trabalho (pp. 67-118). São Paulo, SP: Atlas.

Estado de Rio Grande do Sul. Secretaria da Justiça e da Segurança. Brigada Militar. Boletim 02/2002. (2002). Edital de Concurso público para ingresso no Curso Superior de Polícia Militar, Quadro de Oficiais do Estado Maior da Brigada Militar, posto de Capitão. Porto Alegre, RS. Retirado em 30 jul. 2003, de http://www.faurgs.ufrgs.br/concursos/SJSBM2/ SJSBMEditalCapitão.asp.

Foucault, M. (2002). Vigiar e punir: História da violência nas prisões. Petrópolis, RJ: Vozes.

Lei Complementar n. 10.990 (1997). "Estatuto dos Servidores Militares da Brigada Militar do Estado do Rio Grande do Sul." Diário Oficial do Estado, promulgada em 18 de agosto de 1997. Porto Alegre, RS. 
Lei n. 10.991 (1997). "Organização Básica da Brigada Militar do Estado do Rio Grande do Sul.” Diário Oficial do Estado, promulgada em 18 de agosto de 1997. Porto Alegre, RS.

Merlo, A. R. C. (2002). Psicodinâmica do trabalho. In M. G. Jacques \& W. Codo (Eds.), Saúde mental \& trabalho - Leituras (pp. 130-142). Petrópolis, RJ: Vozes.

Oliveira, P. A. B. (2002). Trabalho prescrito e trabalho real. In A. D. Cattani (Ed.), Trabalho e tecnologia - Dicionário crítico (pp. 350-353). Petrópolis, RJ: Vozes; Porto Alegre, RS: Editora da Universidade Federal do Rio Grande do Sul.

Pinheiro, V. M., \& Álvares, P. B. (1993). Guia de consultas: DPOs \& Nils/Op da BM. Porto Alegre, RS: Metrópole.

Submissão: $22 / 09 / 2005$

$1^{a}$ revisão: $24 / 03 / 2005$ Aceite final: $24 / 11 / 2005$ 